\title{
Development challenges in South Korea: reflection on the Saemangeum land reclamation project
}

\author{
Desafíos de desarrollo en Corea del Sur: reflexión sobre \\ el proyecto de recuperación de tierras del estuario de Saemangeum
}

Eun Ah Hong (Universitat Jaume I, Spain)

Bibliographic citation: Hong, E. A. (2022). Development challenges in South Korea: reflection on the Saemangeum land reclamation project. Disjuntiva, 3(1), 9-17. https://doi.org/10.14198/DISJUNTIVA2022.3.1.1

\section{Resumen}

Este artículo examina cuáles son los retos del desarrollo en Corea del Sur a partir del análisis del caso del proyecto de recuperación de tierras de Saemengeum desde un enfoque crítico con el desarrollo. Al explorar el proyecto de recuperación de tierras Saemangeum liderado por el Estado, que finalmente adoptó la retórica de la sostenibilidad, el artículo examina el impacto del desarrollo estatal en el medio ambiente y la sostenibilidad de la comunidad. Se muestra cómo el conocimiento local tradicional de un modo de vida sostenible se ha desvanecido, irónicamente a través del proyecto de desarrollo "ecológico" que supuestamente reconoce el espacio cultural de los pescadores y la forma en que estos se relacionan entre sí y con la naturaleza. Al observar el proyecto Saemangeum, que demuestra los desafíos de desarrollo existentes en Corea del Sur, el artículo cuestiona cómo alcanzar un futuro pacífico y sostenible.

\section{Palabras claves}

Proyecto de recuperación de tierras de Saemangeum; discurso del desarrollo; desarrollo ecológico; sostenibilidad comunitaria; conocimiento local tradicional.

\begin{abstract}
This article examines what the development challenges are in South Korea by specifically analyzing the case of the Saemangeum land reclamation project from a critical approach to development. By exploring the state-led Saemangeum land reclamation project, which in the end adopted the rhetoric of sustainability, the article examines the impact of state development on the environment and community sustainability. It is shown how the traditional local knowledge of sustainable living has vanished, ironically through the 'ecofriendly' development project that supposedly recognizes the cultural space of the fishers and the way they relate to each other and nature. By observing the Saemangeum project, which demonstrates the existing development challenges in South Korea, the article questions how to reach a peaceful and sustainable future.
\end{abstract}

\section{Key words}

Saemangeum land reclamation project; development discourse; eco-friendly development; community sustainability; traditional local knowledge.

Eun Ah Hong: https://orcid.org/0000-0003-2713-8571 


\section{Introduction}

To get out of the extreme misery and poverty principally caused by the civil war (1950-1953) after the Japanese colonization (1910-1945) of the peninsula, war-torn South Korea desperately applied a top-down development approach mainly led by the state authority. As a result, South Korea has achieved remarkable economic growth. However, due to the way South Korea has developed economically, not only has the environmental degradation worsened but the marginalization of communities has also continued. In other words, it shows that the current economic system inevitably causes environmental degradation and marginalization.

Since such an economic system intensified social-environmental conflicts worldwide, social-environmental sustainability has become a more important issue of world politics. Following that, there have been different attempts to shift the growth paradigm toward a more sustainable and inclusive path (e.g., sustainable development, human development, inclusive development, etc.). However, in an effort to maintain control, the power of big capitalist enterprises and corporate groups also continues to evolve by adopting new alternative ideas to maintain their influence, which has been demonstrated through the process of the Saemangeum project. To sum up, it seems that the development discourse, which is excessively obsessed with economic growth backed up by scientific technologies, is continuously repeated through different names, such as green growth or sustainable development.

In fact, since the 1992 Rio summit, the values of the neoliberal agenda that includes "free trade, limited regulation, market mechanisms, economic growth, and conservative fiscal and monetary policies" (Castro, 2004: 197) have been emphasized. Since then, the participation of large corporations has become more noticeable while promoting green consumerism (Redclift, 2005). Besides, different capitalistic solutions to solve environmental issues have been provided especially through the technological solutions. However, under the logic of capitalistic sustainable development, it is inevitable to avoid the commodification of nature, and such a result would influence people, especially those who heavily depend on nature.

To illustrate this point, this article observes how the Saemangeum project, which adopted supposed eco-friendly gradual development, still brought about environmental degradation and destroyed the local traditional knowledge of sustainable and peaceful living. By pointing out the existing development challenges in South Korea, this article questions how to reach a peaceful and sustainable future. For that, the qualitative research technique is used heavily based on a wide variety of secondary sources, including academic journals, books, and newspapers and so forth.

\section{Critical perspectives on development}

With the famous speech of President Truman (1945-1953) in 1949, the 'era of development' began with the hope of terminating "underdevelopment" based on modern technology and technological knowledge, which will support a great production (1999). Since the birth of the concept, 'underdeveloped', indicating the undignified condition or economically backward areas, more than two billion of the world population have suddenly lost their name while being called 'underdeveloped' (Esteva, 2010; Rist, 2008). In other words, those who are 'underdeveloped' stopped being what they were (by denying their identity and values) in order to follow "the 'development path' mapped out for them by others" (Rist, 2008: 79).

Accordingly, underdevelopment can be understood as a lack of sufficient capital resources and the technologies to efficiently explore natural resources instead of the result of historical circumstances (e.g., colonization, imperialism, etc. as Piqueras, 2008, develops it in detail). Thus, the new invention of development mainly promotes economic growth through capital investment and technological support to replicate a western lifestyle. As Rist emphasizes, "the 'development age' was the period when economic spread everywhere, with the raising of GDP as the number of imperative" (2008: 79). Since economic growth became the most important key to terminate underdevelopment, the modernization process, which ultimately involves industrialization and urbanization, is only expected through the development process (Rahnema and Bawtree, 1997).

However, instead of completing the expected promises, development causes problems of its own. As the UN report on social policy and planning points out, "the fact that development either leaves behind, or in some ways even create, large areas of poverty, stagnation, marginality and actual exclusion from social and economic progress is too obvious and too urgent to be overlooked" (UN 1971 in Esteva, 2010: 9-10). But also, the development further brought new problems, such as environmental degradation and cultural alienation (Rahnema and Bawtree, 1997). In fact, due to the intense social-environmental conflicts, different approaches to development have been proposed, which in a way means the failure of development. However, it seems that the idea of development is still the most powerful discourse as world politics 
repeatedly concerns economic growth as a main part of development. Thus, similar problems are tirelessly repeated through the different approaches to development.

The main approach to development is "purely Western genealogy" (Esteva, 2010:5), which completely ignores different alternatives to development. As the reality has been colonized by the development discourse, there have been consistent struggles of those who hope to construct different realities in the process (Escobar, 1995). Perhaps this can be the main reason why sustainable development, for instance, cannot sustainably develop, but rather sustains development. As the hegemonic discourse of development solely relies on the Western knowledge system, indigenous people's culture and knowledge became excluded by adopting the hegemonic idea as the truth (Escobar, 1995). As Rist points out, development can be seen as "a belief and a series of practices which form a single whole in spite of contradictions between them" (Rist, 2008: 24). Meanwhile, people in Third World countries started to think of themselves as "inferior, underdeveloped and ignorant and to doubt the value of their own culture" (Rahnema and Bawtree, 1997: 92).

Consequently, the development discourse that is "a top-down, ethnocentric and technocratic approach, has treated people and culture as abstract concepts, statistical figures to be moved up and down in the charts of progress" (Rahnema and Bawtree 1997, 91). Thus, challenging the development discourse, which is deeply rooted in the development system in South Korea, is inevitable to reach 'real' alternative development.

\section{The Saemangeum land reclamation project}

The Saemangeum land reclamation project (see Figure 1) was to create 409 square kilometers of space, including 118 square kilometers of an artificial lake and 291 square kilometers of claimed land by constructing a $33 \mathrm{~km}$ long seawall, which would stop rivers from reaching the sea (Saemangeum Development and Investment Agency n/d). The Saemangeum project proposal was a strategic election pledge in the 1987 presidential elections to win more votes in the North Jeolla province. Initially the idea had the full support of the Ministry of Agriculture (in charge of the project) and the North Jeolla provincial government (main interest group) (Lee et al., 2006).

Figure 1. A Map of Korea and the location of the Saemangeum tidal flats

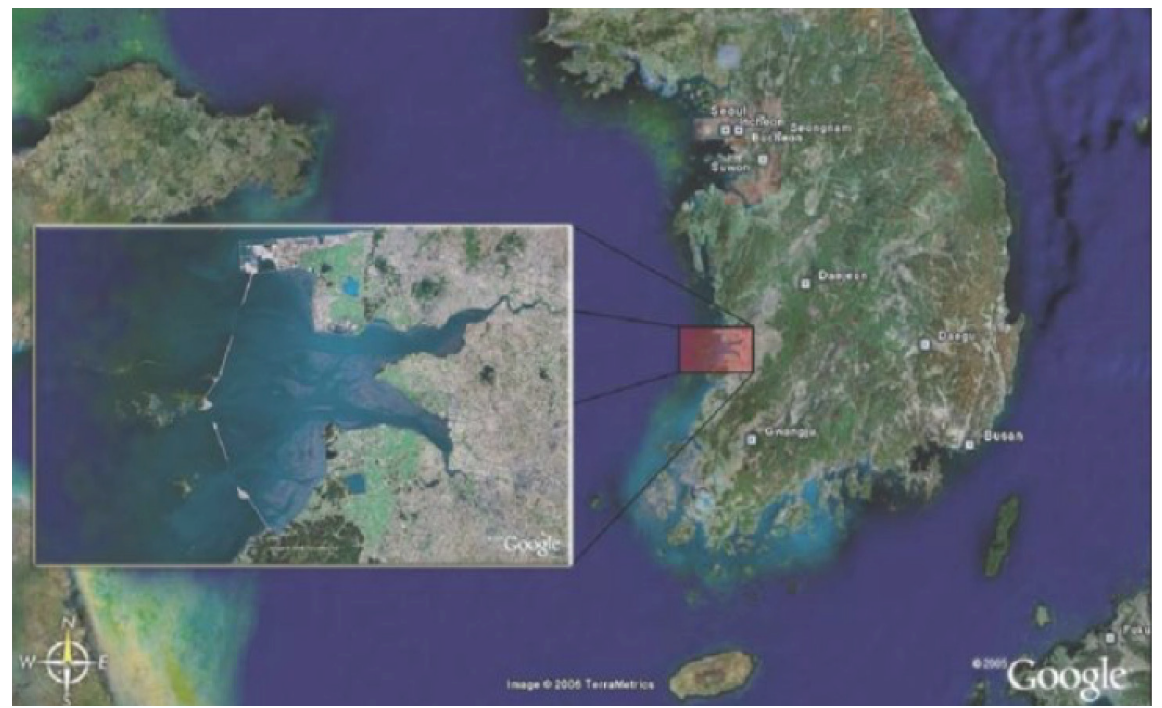

Fuente: (Kim, 2007: 27)

The project, which was officially initiated in 1991, was originally proposed to expand territory, enlarge water resources, prepare substitute agricultural land, and construct welfare farming and fishing villages. It was supposed to be a symbol of the economic development of the North Jeolla province (Lee et al., 2006), and initially the idea was fully supported by the majority of local residents who hoped the project would improve their livelihoods. As such the project quickly became an important topic for debate in both provincial and central politics. 
Public perception of the project started to change in 1996, when a similar land reclamation project in Gyeonggi province limited tidal water flows which resulted in the pollution of Sihwa Lake. Given this example, some people and environmental groups feared that the same could happen in Saemangeum Lake following the construction of the seawall. The Saemangeum tidal flat is naturally filled with rich "fishery resources, biodiversity, seascape and as a stopover for migratory birds" (Kho et al., 2010), and the people in the nearby fishing villages largely depend on the sea and the mudflats for their livelihoods. Therefore, environmental groups, religious groups, and some local residents gathered to oppose the Saemangeum project based on their concerns over the lake while highlighting other issues and concerns over environmental degradation and damage on local communities.

The Korean Board of Audit and Inspection conducted a special inspection of the Saemangeum project in 1998 and strongly supported the claims of anti-Saemangeum groups. Therefore, the Board recommended reconsideration of the project based on its environmental impact and economic feasibility. However, the pro-development groups also strategically formed a coalition, and the provincial government in support of the project requested another reexamination of the project in order to pressure the central government to move forward with the project. Uncertain on how to proceed, the central government deferred the construction of the project until 2001 when the ruling party lost the by-election against the opposition and decided to continue with the Saemangeum project. To appease both sides, the project was supposed to be implemented in a more eco-friendly and gradual process. Despite these efforts to compromise, the conflict between the pro- and anti-project groups continued to deepen.

A group of different religious practitioners came together to protest by completing the Sambo-Ilbae (three steps and one bow) march of $305 \mathrm{~km}$ distance from Saemangeum to Seoul, which was highly successful in raising people's environmental attention. They also submitted a lawsuit to halt the completion of the project, which eventually would go all the way to the Supreme Court. On the other side, the project advocate groups held a big campaign to support the Saemangeum project, and the residents of North Jeolla province welcomed the project for the promised economic benefits and expressed their deep-rooted sense of resentment for the region's marginalized position in Korean politics and economy (Yuk, 2005). The conflict and discussion between pro-and anti-project groups remained until March 2006 when the Supreme Court announced its decision to allow the project to be completed. Immediately following the decision, the government completed the seawall in April 2006.

However, even after the construction of the seawall, the conflict continued given the uncertainty of how to use the claimed land. The purpose of the original plan changed with the changing political-economic conditions. Accordingly, during the regime of President Myung-Bak Lee (2008-2013), the original purpose of the project changed to converting Saemangeum into the center for the industrial and economic center of Northeast Asia. Thus, 'the Special Act for the Promotion of the Saemangeum Project' that focused more on its industrial advantages passed in 2008, and the Master plan was proposed in 2011. However, the Master Plan has been constantly modified since then. The government under President Geun-Hye Park (2013-2017) proposed the new plan of 'the Korea-China Free Trade Industry Complex'. However, it was later replaced by the renewable energy project, which was proposed in 2018 during the current government of President Jae-In Moon (2017- present).

In the end, the authority of the Saemangeum project proudly announced the Saemangeum project as "the new land, which will give birth to a new civilization for green growth and clean environment covering economy, industry, and tourism" (Saemangeum Development and Investment Agency, n/d). Furthermore, the Saemangeum project is supposed to provide hope and dreams for the current generation, and opportunities and chances for future generations (ibid.). Accordingly, the current authority of the project claimed that the Saemangeum project is "a frontrunner of green growth that promotes an environmentally-friendly project once all conflicts and confrontations are finally over" (ibid.).

\section{Consequences of the project: environmental degradation and marginalization}

Since the completion of the seawall, seawater has stopped flowing into the mudflats, and everything has changed. As the villagers stated, the wetland, which is the "most effective carbon sinks on our planet" (Ramsar, n/d), is dead as it has turned into dry land. The research shows that 95 percent of the tidal flat became desertified (Hahm et al., 2011). Accordingly, a variety of critters, including varied shellfish, clams, worms, webfoot octopus, and long-arm octopus have all died out. Furthermore, the devastated ecosystem has influenced other wildlife, especially the migratory birds that feed on the tidal flats. 
Moreover, as the water cannot circulate, the entire ecosystem within Saemangeum Lake has suffered. Many species of fish disappeared in the middle of the construction process as the quality of water deteriorated as sediment from the Dongjin and Mangyeong Rivers piled up inside the lake (Hahm, 2004). Research that investigates the changes of the sea ecosystem (before 1991, 1991-2006, 2006-2011) demonstrates that Chemical Oxygen Demand (COD) has increased while salinity has decreased (Hahm et al., 2011). Moreover, the difference in the tidal range decreased by about 20 percent after the construction of the seawall (bid.).

In order to improve the water quality, the government has invested billions of dollars, and the water quality has been 'controlled' with the help of modern technology under the provision of the Ministry of Environment (Betts, n/d). However, the local fishers insisted on the necessity of immediate seawater circulation to improve the water quality in the lake. Recently, the research commissioned by the Ministry of Environment confirmed that the water quality had indeed worsened, and recommended to increase seawater circulation by 6.5 times (from 3,608,000,000 ton to 23,590,000,000 ton per year) (Choi, 2020).

After the completion of the seawall, most of the fishing villages suffered from economic difficulty unlike what the project committee expected. The official records of fisheries cooperative unions show that both the amount of money for selling and the amount of marine product selling has decreased, especially for the fishers who mainly live off the customary fishery and mudflat fishery. Total marine product output before and after the Saemangeum construction in North Jeolla province shows a big difference. For instance, total marine product output in North Jeolla province was 150,234 tons in 1990 and 134,819 tons in 1991; however, after the seawall construction, the total output in the region was decreased to 81,114 ton in 2010 and 71,309 ton in 2011 (Park, 2019). The difference in total marine product output (1991 to 2011) in Gunsan (59,543 to 31,111 ton), Gimje (2,759 to 0 ton), and Buan (9,293 to 922 ton) is even more dramatic since these cities are directly affected by the Saemangeum project (ibid.).

Furthermore, the loss of the mudflat severely affected the livelihood of the villagers as they depend heavily on mudflat fishing, which is considered the essential family income for living and educational expenses, especially for lower-income families and the elderly who cannot easily adapt to the sudden changes (Hahm, 2004). However, the loss of the mudflats not only caused economic suffering but also social and psychological suffering by disconnecting the local population from nature (Ku and Hong, 2006).

The result of this sudden artificial change also influenced the way villagers interact with the sea. As the seawall caused the contamination of the mudflats, which in turn caused a decrease in yield, the work on the sea and the mudflat became extremely competitive because of the scarcity of the marine resources in the lake (Ku and Hong, 2006). In other words, by enclosing collective property, there was greater inequality in resource distribution and more severe degradation of nature, which ultimately led to overexploitation.

Hence, the fishers have adopted a new but unsustainable principle, which is "sweeping out everything" (Hahm et al., 2011: 33). The regulations and community agreements previously practiced among fishers are no longer respected due to the environmental degradation caused by the 'eco-friendly' development project. The fishers no longer practice the traditional fishing techniques nor value the traditional knowledge as their main goals have changed to maximizing their profit. Moreover, the fishers believe that whether they sweep out everything or not, the marine life will die out regardless as the marine ecosystem has been destroyed (Ku and Hong, 2011). Therefore, even though it is illegal to fish inside the lake, the fishers, especially the ones with big ships, began to sweep out everything in the sea where no regulation exists (ibid.).

In addition, more destructive ways of fishing are being used by adopting dangerous techniques and tools. Various new tools and techniques have been invented to maximize productivity. For instance, a small boat called cha-cha-cha that is furnished with a motor engine, pipes, hoes, and a net is designed to catch clams effectively and indiscriminately by using the power of an engine, especially once the mudflat was submerged under the water of the lake (Hahm, 2010). This way of fishing was banned by the fishers in the past since such a tool sweeps out everything, and eventually destroys the marine ecosystem on which the villagers depend for their livelihoods. In the past, the fishers preferred to use simple hand tools like "geurae" or "galgui", which avoid catching indiscriminately (ibid.). However, as the condition of the sea worsened, the fishers even started using a tool like a trawl net, which had been strongly forbidden in the fishing community before (Hahm et al., 2011).

The limited marine resources led to the competitive and profit-oriented way of fishing, and the villagers further invented different tools to increase the yield of fish and shellfish, which will inevitably become extinct (Hahm et al., 2011). As the fishers have repeatedly argued, they understand how bad it is to use such unsustainable tools, yet they continue applying these unsustainable practices simply to survive (Hahm, 2010). It demonstrates that the sudden environmental changes not only caused the ultimate depletion of shellfish and fish but also the traditional fishing 
practice. As the villagers realized that resources in the sea would soon disappear, they left the traditional and ethical practices of fishing for unsustainable and destructive ones.

Fishing communities function as "social safety networks" meaning that there is no retirement and there is no need to worry about social security (Kim, 2011). Those who are able to work take care of the members of their community who can no longer work. Fishing communities have unique cultures and shared values that are closely interconnected to their livelihoods (ibid.). The sea is an open space where abundant resources can be found although it is also unpredictable and dangerous at times. Fishers understand well that it can never be private property. Thus, fairness and equality are the most important values in fishing communities: resources are equally shared and fairly distributed; overfishing and acts of polluting the sea are forbidden by an unspoken oath (ibid.). Strict codes of practices among fishers have been observed for generations. However, the fishing communities affected by the Saemangeum project stopped practicing sustainable and peaceful fishing practices as the cultural space of their community was taken over by the 'eco-friendly' development project.

\section{Justification of the project: eco-friendly gradual development}

Due to the social-environmental movement against the Saemangeum project, the central government tried to be more environmentally conscientious by adopting the eco-friendly gradual development, which was proposed as "an environmental problem-solving discourse" (Park, 2015: 23). However, the Saemangeum project demonstrates that the supposedly eco-friendly development, which mainly relied on a scientific-technology solution, not only failed to address the essential socio-political issues but furthermore justified the socio-political structures that promote the development discourse (ibid.). Thus, while the environmental problems were superficially highlighted through eco-friendly gradual development, the questions of injustice and inequality caused by the socio-political system were ignored.

The outcome of the project indeed demonstrates how the green rhetoric of the project has been exclusively used to revive a developmental discourse that prioritizes economic growth while simply ignoring the social-environmental conflicts and confrontations. Consequently, the core values highlighted through the process of the project are economic growth and economic efficiency. In other words, the driving force behind the way to perceive the mudflat is commercialization, marketization, and privatization. In this view, the Saemangeum project seems to be simply replicating the development discourse, which "has relied exclusively on one knowledge system" that inevitably causes marginalization by rejecting different knowledge systems" (Escobar, 1995: 13). In fact, while scientific experts were considered to produce "objective" knowledge, which formed the basis for the decision-making about environmental problems, non-experts were disqualified to participate in the process.

Within the discussion of sustainability/sustainable development, scientific technology plays a key role in the link between development and the environment (Haque, 1991). Therefore, some experts see sustainable development as "a political vision underpinned by the theory of ecological modernization" (Olsson et al, 2014: 5). The theory of ecological modernization indeed highlights the possibility of reaching both economic growth and environmental improvement (Jänicke and Weidner, 1997) as it provides a constructive/systematic approach to solve environmental problems grounded in scientific and technological knowledge (Mol and Spaargaren, 1993). Thus, there is no need to make tough choices between economic growth and environmental protection since ecological modernization offers "a plausible strategy for transforming industrial society into a radically different and more environmentally defensible (but still capitalist) alternative" (Dryzek, 1997: 143). Ecological modernization helps replace "the earlier phase of crude, environmentally damaging, industrial capitalism" (Pepper, 1998: 2). Thus, challenging the current socio-political system is not necessary. In other words, ecological modernization permits the system of capitalism to remain.

However, as the Saemangeum case has demonstrated, the eco-efficiency approach to sustainable development that is strongly linked to economic interest focuses on how to manage natural resources effectively with the help of technology or natural preservation. Thus, the importance of the way the fishers perceive and value nature (e.g., mudflat, sea) was not carefully observed through the discussion of the Saemangeum project. In conclusion, even though there was promising technological support, environmental degradation, which directly affected the livelihood of the villagers, occurred. In fact, economic growth obviously requires the use of the environment (Martinez-Alier, 2002). Thus, economic growth not only produces more waste but also damages natural systems even with new technological support (ibid.). New technology can be a tool to decrease environmental problems/damage, but not a solution to it. In other words, "new technologies are not necessarily a way out for the conflict between the economy and the environment" (ibid.: 12). 
In fact, many social-environmental conflicts occur as "the poor trying to retain under their control the natural resources threatened by state takeover or by the advance of the generalized market system" (Guha and Martinez-Alier, 2013: xxi). As the Saemangeum case also has demonstrated, community people who depend heavily on natural resources lost access while the state authority has gained privileged access to natural resources. On top of this, the supposedly ecofriendly development caused a burden of environmental degradation on the community's lifestyle. In the end, many social-environmental conflicts occur to challenge such mainstream environmentalism (eco-efficiency approach) since it often ignores to observe and include how "subordinated social groups, such as peasants and fisherfolk" perceive and value nature (Guha and Martinez-Alier, 2013: xxi).

\section{Conclusion}

As the article has shown, the state-led Saemangeum reclamation project has destroyed the marine ecosystem and a sustainable local economy, which had operated on the basis of the local culture and traditions of living harmoniously with/within nature. The villagers who had been living sustainably lost their traditional knowledge and values due to environmental degradation.

The Saemangeum project shows that the very foundation of the development process applied in South Korea is still economic growth, despite the green rhetoric used by the government. From the pro-development groups' perspective, the mudflats and the sea are only valuable when they are used for the purpose of economic growth. This focus on economic development that is central to all political debates marginalizes other perspectives. In the case of Saemangeum the local villagers' traditional knowledge and ways of relating to nature were subverted, leading to even greater environmental destruction and socio-economic inequality.

In order for South Korea's future development to become truly sustainable, the entire system of focusing exclusively on economic growth must be challenged. For that it will be important to recognize the value of traditional knowledge and practices that promote living in harmony with nature and respecting all life forms. In this regard, the local knowledge system of sustainable living that was completely ignored through the Saemangeum development project could be revived and become a valuable asset to move toward a more peaceful and sustainable future. While the Saemangeum project resulted in environmental destruction and marginalization, the movement to stop the project did influence the general debate over environmental sustainability in South Korean society, expanding the discussion to include topics such as the rights of future generations and non-human beings. Hopefully, the lessons learned from the Saemangeum project can prevent future development projects from repeating the same mistakes, by including local knowledge and expanding the understanding of sustainability beyond economic growth and ecological modernization.

\section{Bibliography}

Betts, B. (2018). Last Murmurations of a Destroyed Wetland. Korea Expose, January 5th. https://www.koreaexpose.com/ saemangeum-wetland-destroyed-korea/

Castro, C. J. (2004). “Sustainable Development Mainstream and Critical Perspectives”. Organization \& Environment, 17 (2), 195-225. https://doi.org/10.1177/1086026604264910.

Choi, W.R. (2020). [단독] 29년 갈등 끝에... 정부 “새만금 바닷물 흘러야 산다 [In Eng. After 29 years of conflict ... the government confirms "the necessity of sea circulation to revive Saemangeum"], Hankyoreh, October $\left.7^{\text {th }}\right)$ https:// www.hani.co.kr/arti/society/environment/964700.html

Dryzek, J. (1997). The Politics of the Earth: Environmental Discourse. Oxford: Oxford University Press.

Escobar, A. (1995). Encountering Development: The Making and Unmaking of the Third World. Princeton, New Jersey: Princeton University Press.

Esteva, G. (2010). “Development”. In: S. Wolfgang (ed.), The Development Dictionary: A Guide to Knowledge as Power. London: Zed Books, 1-23. 
Guha, R. and Martinez-Alier, J. (2013). Varieties of environmentalism: essays North and South. London: Routledge. https:// doi.org/10.4324/9781315070766.

Hahm, H. (2004). "Ecological Crisis and Women: The Case of Saemangum Reclamation Project”. ECO, 7, $150-170$.

Hahm, H. (2010). "Life after Saemangeum Restoration Project”. Journal of the Korean Society for Marine Environment \& Energy, 13 (4), 313-326.

Hahm, H., Jung, M. and Lee, D. (2011). "A Study of Interactional Relations between Marine Ecology and Fishery in the Area of Saemangeum". ECO, 15 (2), 7-37.

Haque, M. M. (1991). "Sustainable development and environment: a challenge to technology choice decision-making". Project Appraisal 6 (3), 149-157. https://doi.org/10.1080/02688867.1991.9726812

Jänicke, M. and Weidner, H. (1997). National Environmental Policies: A Comparative Study of Capacity-Building. Springer. https://doi.org/10.1007/978-3-642-60507-9.

Kho, C., Ryu, J. and Kim, J. (2010). “The Saemangeum: History and Controversy”. Journal of the Korean Society for Marine Environment \& Energy, 13 (4), 327-334.

Kim, J. (2011). “Threats to Village Fisheries and the Recognition of Its Values”. Journal of the Island Culture, 38, $245-272$.

Kim, R. K. (2007). "Principles of Sustainable Development in Korean Environmental Law: Towards the Earth Charter Principles". The New Zealand Postgraduate Law e-Journal, 41-44.

Ku, D. and Hong, D. (2011). "A Study on the Social Impacts of Saemangeum Project: Focused on the changes after the completion of the last tide embankment construction in 2006". ECO, 15 (2), 39-80.

Lee, S.W., Kim, J.R., Kim, J.H., Rho, S.Y., Lee, E.K., Im, K.H. and Choi, Y.C. (2006). The case study of Saemangeum Reclamation Development Project. http://www.nl.go.kr/app/nl/search/common/download.jsp?file id=FILE-00008153252

Martinez-Alier, J. (2002). The Environmentalism of the poor: a study of ecological conflicts and valuation. Cheltenham: Edward Elgar Publishing. https://doi.org/10.4337/9781843765486.

Mol, A. and Spaargaren. G. (1993). "Environment, Modernity and the Risk-Society: The Apocalyptic Horizon of Environmental Reform”. International Sociology, 8 (4), 431-459. https://doi.org/10.1177/026858093008004003

Olsson, L., Hourcade, J. and Kohler, J. (2014). "Sustainable Development in a Globalized World”. Journal of Environment \&Development 23 (1), 3-14. https://doi.org/10.1177/1070496514521418

Park, J.M. (2019, December 08). 새만금 간척사업, 수산업 13조 8000억 원 손실입혀 [In Eng. Saemangeum land reclamation project caused economic loss on fishing industry], Hyundae Haeyang, December 8th. http://www.hdhy. co.kr/news/articleView.html?idxno $=10852$

Park, S.Y. (2015). "Social Conflicts and Hegemonic Articulation on the Saemangeum Reclamation Project in South Korea". Development and Society 44 (1), 1-27. https://doi.org/10.21588/dns.2015.44.1.001.

Pepper, D. (1998). “Sustainable development and ecological modernization: A radical homocentric perspective”. Sustainable Development, 6 (1), 1-7. https://doi.org/10.1002/(SICI)1099-1719(199803)6:1<1::AID-SD83>3.0.CO;2-8

Piqueras, A.I. (2008). “De la colonización al desarrollo, del paralelo devenir del sistema mundial, la desigualdad, el desarrollo y la cooperación”. In Several authors, Desarrollo y cooperación: un análisis crítico. Valencia: Tirant lo Blanc.

Rahnema, M. and Bawtree, V. (1997). The Post- Development Reader. London \& New Jersey: Zed Books.

Ramsar. (n.d.). Wetlands and Climate Change. Retrieved November 20, 2020, from https://www.ramsar.org/news/ wetlands-and-climate-change\#: : text=In $\% 202018 \% 2 \mathrm{C} \% 20$ Parties $\% 20$ to $\% 20$ the, and $\% 20$ adaptation $\% 20$ to $\% 20$ climate $\% 20$ change 
Redclift, M. (2005). "Sustainable Development (1987-2005): An Oxymoron Comes of Age". Sustainable Development, 13, 212-227. https://doi.org/10.1002/sd.281.

Rist, G. (2008). The History of Development: From Western Origins to Global Faith. London: Zed Books Ltd.

Saemangeum Development and Investment Agency. (n.d.). Saemangeum Project. Retrieved November 16, 2020. from http://www.saemangeum.go.kr/sda/cmm/main/enMainPage.do

Yuk, G.H. (2005). "Social Issues occurred through the Saemangeum project and solution". Korean Maritime Institute, 246, $18-27$. 